\title{
Research progress of microstructure control for aluminium solidification process
}

\author{
WANG XiangJie $^{1 *}$, LUO XiaoXiong ${ }^{2}$, CONG FuGuan ${ }^{3} \&$ CUI JianZhong ${ }^{1}$ \\ ${ }^{1}$ Key Laboratory of Electromagnetic Processing of Materials, Ministry of Education, Northeastern University, Shenyang 110819, China; \\ ${ }^{2}$ Aluminum Corporation of China Ruimin Co., Fuzhou 350015, China; \\ ${ }^{3}$ Aluminum Corporation of China Northeast Light Alloy Co., Harbin 150060, China
}

Received September 19, 2012; accepted October 30, 2012; published online December 1, 2012

\begin{abstract}
Aluminum has been the secondly main metallic material in the world, whose mechanical properties are very important for industrial applications. The sizes and shapes of grains are important in determining the performance in structural applications. How to control the microstructure during solidification process has been a research focus. This paper gives an overview on the recent progress in microstructure control for aluminium alloys solidification process, and introduces the different methods to control the microstructure in detail. The mechanisms of microstructure control for different methods are also discussed. Finally, a brief prospect on future work is presented.
\end{abstract}

aluminium alloy, microstructure control, solidification, grain refinement

Citation: Wang X J, Luo X X, Cong F G, et al. Research progress of microstructure control for aluminium solidification process. Chin Sci Bull, 2013, 58: 468-473, doi: 10.1007/s11434-012-5585-1

Steel is the most widely used in structural and functional applications, and high performance steels have been a new research focus in recent years [1-10]. Aluminum is the richest metallic element in the earth, which has been the secondly main metallic material in the world. Fracture properties of materials are very important for industrial applications, and different mathematical models have been developed to simulate the fracture of materials [11-14]. For aluminium alloys, the sizes and shapes of the grains can be important in determining the performance in structural applications. Fine grain size is beneficial to aluminium alloys for ambient temperature structural use, because it simultaneously gives higher strength and greater toughness. Additionally, grain refinement can decrease the size of defects and increase the resistance to hot tearing, especially for producing large, superhigh aluminium alloy ingots [15]. On the other hand, single crystal with almost no grain boundary and nanomaterials are important in determining the performance of functional applications [16-18]. Zhang et al. [19]

*Corresponding author (email: wangxj@epm.neu.edu.cn) simulated the microstructure evolution during the directional solidification process. Aluminum foam with low density is attractive as cushion material, and which can be used for mitigating shocks, absorbing impact energies, etc. [20]. Additionally, amorphous alloys are the recent developed metallic materials, and exhibit many excellent properties [21].

As mentioned above, metal materials are used widely in human society, and plenty of research has been done in material science recently [22]. The sizes and shapes of the grains are crucial for the mechanical properties, and they are determined by the solidification process. Solidification process is a phase transition, in which a liquid turns into a solid when its temperature is lower than its freezing point. It occurs in a wide range of industrial processes, including conventional casting and single crystal growth. In order to reveal the solidification process intuitively, transparent model materials can be used to study the solidification process [23]. The melt flow during solidification process can be seen as the fluid flows with different viscosities under different temperatures. The porous media are usually used to simulate the melt flow during the solidification process. Re- 
searches about viscosity, convection and solution of equation have been carried out, and different meshing technologies, principles and models have been developed for finite element analysis [24-33].

In some practical cases, the final grain size and microstructure are the result of the solid state process. The recrystallization following mechanical deformation and deformation temperature are important for the plastic deformation process [34-36]. In this paper, we mainly discuss the grain control of as-solidified structure during the aluminium alloys solidification process. For solidification structure control, there are many methods such as adding alloy elements, adding grain refiner, applying the physical fields, etc.

\section{Structure control by adding alloy elements}

Many experimental results show that adding some alloy element into the aluminium alloy can affect the structure and improve the mechanical properties. There are a wide variety of alloy elements, and their effects and mechanisms are different. How to choose the kind of elements and how to control the content of elements to obtain optimum alloying effect have been investigated widely. The rare earth elements and transition elements are usually chosen to alloy the aluminium alloy. The second phase particles formed by the rare earth element or transition element can be heterogeneous nucleation. The solidification structure of aluminium alloy can be refined, the growth of grain can be restrained during the recrystallization process, and the aluminium alloy with good superplasticity can be obtained [37].

The addition of rare earths in aluminium alloys can refine the grains, purify the melt and reduce the gas and inclusion contents. So, the comprehensive properties of aluminium alloys are improved [38]. The existing researches show that the alloying effect of $\mathrm{Sc}$ is the most obvious among all the alloying rare earth elements. When the Sc element is added into the $\mathrm{Al}-\mathrm{Cu}-\mathrm{Mg}-\mathrm{Ag}$ alloy, approximately $70 \%$ of the Sc added into aluminium alloy are fixed in the supersaturated solid solution. Two thirds of Sc in the supersaturated solid solution are consumed by the formation of a dispersion of nanoscale $\mathrm{Al}_{3} \mathrm{Sc}$ particles within the $\mathrm{Al}$ matrix during the homogenisation annealing process. A third of the Sc are consumed as the formation of the $\mathrm{W}$-phase because of Sc diffusion into the primary $\theta$-phase, which leads to its transformation into the $\mathrm{W}$-phase [39]. However, the Sc element is very expensive, so the aluminium alloys containing rare earth element $\mathrm{Sc}$ are too expensive to be widely used in industrial areas. Nie and his group [40] found that rare earth element $\mathrm{Er}$ is a cheap and effective alloying element for aluminium alloy. The nano-scale $\mathrm{Al}_{3} \mathrm{Er}$ particles can form in aluminium alloys containing $\mathrm{Er}$, and the composite phase $\mathrm{Al}_{3}\left(\mathrm{Zr}_{x} \mathrm{Er}_{1-x}\right)$ can form due to the interaction of $\mathrm{Er}$ and $\mathrm{Zr}$ in the liquid metal of a high temperature. The $\mathrm{Al}_{3} \mathrm{Er}$ and $\mathrm{Al}_{3}\left(\mathrm{Zr}_{x} \mathrm{Er}_{1-x}\right)$ particles are thermally stable, thus the addition of rare earth element Er can modify the microstructure and improve the mechanical properties. Additionally, the $\mathrm{Al}_{3} \mathrm{Er}$ and $\mathrm{Al}_{3}\left(\mathrm{Zr}_{x} \mathrm{Er}_{1-x}\right)$ particles can also hinder the recrystallization and improve its thermal stability [40].

The transition elements ( $\mathrm{V}, \mathrm{Zr}$, etc.) can be added into the liquid metal to refine the grains and improve the fine-grained superplasticity. The research results show that the trace element vanadium added into 5083 alloy can refine the cast structure and fibrous structure of the rolling sheet, restrain the grain growth during recrystallization, and improve the superplasticity of 5083 aluminium alloy. The size of recrystallized grains of the sheets was reduced from 100 to $20 \mu \mathrm{m}$ as shown in Figure 1, where the high temperature superplastic performance of 5083 sheet was improved and the elongation percentage of 5083 aluminium alloy sheet in $510^{\circ} \mathrm{C}$ was improved from $208 \%$ to $254 \%$ after the addition of trace element vanadium [41]. The transition element $\mathrm{Zr}$ is also usually added into high strength aluminium alloys, and the $\mathrm{Al}_{3} \mathrm{Zr}$ particles can precipitate in grain boundary areas during the homogenization treatment process. The presence of $\mathrm{Al}_{3} \mathrm{Zr}$ particles can promote continuous dynamic recrystallization during the hot extrusion process, and a finegrained structure can be obtained. The $\mathrm{Al}_{3} \mathrm{Zr}$ particles can pin the grain boundary migration. A large flow stress is required for the grain boundary mobility to increase as the amount of $\mathrm{Zr}$ addition increases [42]. The $\mathrm{Al}_{3} \mathrm{Zr}$ particles precipitate in the grain boundary areas, which can lead to the hot-rolling textures. The $\mathrm{Al}_{3} \mathrm{Zr}$ particles which are coherent with aluminium matrix can inhibit the movement of dislocation induced by the plastic deformation. So, the $\mathrm{Al}_{3} \mathrm{Zr}$ particles can decrease the deformation textures and prevent recrystallization, which can increase the material hardness and extend the existence time of peak hardness [43].

The rare earth element Sc and transition element $\mathrm{Zr}$ can also be combined to add into the aluminium alloy [44]. Lidia and his groups [45] added the Sc and $\mathrm{Zr}$ elements into the Al-12Zn-3Mg-1.5Cu alloy. The experimental results showed that a significant grain refinement was observed as the presence of fine primary $\mathrm{Al}_{3}(\mathrm{Zr}, \mathrm{Sc})$ particles when $0.2 \% \mathrm{Zr}$ and $0.3 \% \mathrm{Sc}$ were added into the aluminium alloy.

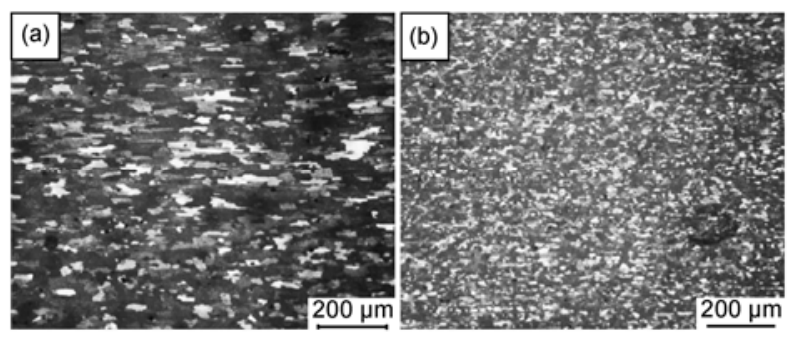

Figure 1 Microstructures of undeformed region. (a) 5083 alloy, (b) 5083 alloy with trace element vanadium. 
The additions of $\mathrm{Sc}$ and $\mathrm{Zr}$ can result in the increase of the microhardness. The heat treatment at $400-460^{\circ} \mathrm{C}$ can increase the microhardness due to the dissolution of alloying elements into the $\mathrm{Al}$ solid solution and the precipitation of $\mathrm{Al}_{3}(\mathrm{Zr}, \mathrm{Sc})$ particles in the $\mathrm{Zr}$ and $\mathrm{Sc}$ contained ribbons [45].

\section{Structure control by grain refiners}

The earliest grain refiner master alloy used in aluminium alloys is the Al-Ti master alloy. On the basis of Al-Ti master alloy, Al-Ti-B master alloy was developed. The effect of grain refinement is improved greatly. However, the density of second phase particles $\left(\mathrm{TiAl}_{3}\right.$ and $\mathrm{TiB}_{2}$ ) in the liquid metal is greater than that of the liquid aluminium alloy. The $\mathrm{TiAl}_{3}$ and $\mathrm{TiB}_{2}$ particles can agglomerate into larger particles during the standing process, and the effect of grain refinement can be invalid six hours after adding them into the liquid metal. In order to avoid the agglomeration of $\mathrm{TiB}_{2}$ during the standing process, Al-Ti-C, Al-Ti-C-B, Al-Ti-C$\mathrm{RE}$ and Al-Ti-B-RE master alloys were developed [46-48]. Doheim et al. [49] evaluated the Al-Ti-C master alloys as grain refiner for aluminium alloys. The second phase particles (TiC) can exist steady and not agglomerate into larger particles. The addition of rare earth element can improve the morphology and distribution of the $\mathrm{TiB}_{2}$ and $\mathrm{TiAl}_{3}$, refine the size of $\mathrm{TiAl}_{3}$ particles, increase the number of heterogeneous nuclei and improve the refinement effect of Al-Ti-B [50]. However, the elements such as $\mathrm{Cr}, \mathrm{Zr}, \mathrm{Mn}$, etc. can interact with the Ti element. The grain refining test results showed that the presence of $\mathrm{Zr}$ in commercial aluminium melts can reduce the effectiveness of Al-5Ti-B master alloy [51].

Quantitative analyses confirmed that the reduction in growth restriction is not the sole reason for poisoning action in the melt. The $\mathrm{Zr}$ element can substitute for titanium in the aluminide and affect the nucleation stage of grain refinement. The existence of $\mathrm{Al}_{3} \mathrm{Ti}$ on $\mathrm{TiB}_{2}$ particles is the key to the nucleation potency [52]. Zhang and his group [43] found that the $\mathrm{Al}_{3} \mathrm{Zr}$ particles can combine with $\mathrm{Al}_{3} \mathrm{Ti}$ particles both in Al-Ti-Zr-C and Al-Ti-Zr-B alloys easily. The potency of $\mathrm{Al}_{3} \mathrm{Ti}$ acting as nucleation particles and grain refiners is impaired and results in the poisoning action. While the $\mathrm{Al}_{3} \mathrm{Zr}$ particles seem not to integrate with $\mathrm{TiC}$ and $\mathrm{TiB}_{2}$ particles though the agglomeration of $\mathrm{TiB}_{2}$ particles exists. The calculation results by using the edge-to-edge matching model indicated that $\mathrm{Al}_{3} \mathrm{Zr}$ has a good crystallographic matching with $\mathrm{Al}_{3} \mathrm{Ti}$ and $\alpha$-Ti particles. The matching with $\mathrm{Al}_{3} \mathrm{Ti}$ and $\alpha$-Ti particles is better than that with $\mathrm{TiC}$ and $\mathrm{TiB}_{2}$ particles. It means that the quantities of the orientation relationships between the matrix and precipitate can be used as a grain refiner for the crystallography theoretical consultation [53].

\section{Structure control by applying the physical fields}

The solidification process of liquid metal is a complex interplay containing many physical effects, and the liquid/solid interface is a free boundary. The latent heat is liberated and conducted away from the interface through the solid and liquid during the solidification process. The pressure on the liquid/solid interface, solidification rate and liquid/solid ratio are the main factors to affect the grain growth, solidification process and structure [54-58]. The melt flow, pressure and temperature distribution can be changed by the mechanical stirring [59] electromagnetic field [60] and ultrasonic wave [61] caused by applying the physical fields, and the solidification structure can be modified.

Mechanical stirring is strong, and always be used for liquid metal treatment. Fan and his group [59] found that the oxide films entrained within melts can be dispersed uniformly in the melt by an intensive stirring and shearing. The dispersed oxide films can act as nucleation centres, so the grain size can be reduced without any addition of grain refiner [59]. Based on the recent melt conditioning by advanced shear technology (MCAST), Zuo et al. [62] carried out an intensive melt shearing on 7032 aluminium alloy. The possibility to transform oxide films from potential defects into potent grain refiners was evaluated by an intensive melt shearing. The experimental results showed that the intensive melt shearing can refine the grains greatly. Additionally, the intensive melt shearing can reduce the size of porosity. The density index can be reduced and the average size of porosity in the samples solidified under partial vacuum is also reduced. For mechanical stirring, the stirring paddle contacts the liquid metal directly, and the stirring paddle could interact with the melt when the stirring paddle is rotating with a high speed and the liquid metal could be polluted.

Electromagnetic stirring is one of the key technologies which can be used to control the solidified structure without contact with liquid metal. The early development of electromagnetic casting (EMC) was described by Getselev [63]. A high frequency electromagnetic field was supplied in order to produce an electromagnetic pressure which was used to balance the static pressure. As there was no contact between the mold and the melt, ingots with good surface quality were obtained and the structure and segregation could be changed by using this technology. The casting, refining and electromagnetic process (CREM) [64] can both refine microstructure and improve surface quality of ingots. The coil surrounded the ingot mold and an alternating current of standard industrial frequency $(50$ or $60 \mathrm{~Hz})$ was supplied. Under the effect of the periodic current, the inductor generates an alternating magnetic field and the melt can be inductively stirred. The constrained effect of electromagnetic forces reduces the contact height between the melt and mold, but the dome height which influences the thickness of the 
segregation is hard to control.

Based on the CREM process, a lower frequency electromagnetic field was applied in the direct chill casting process by Cui and his coworkers [65] to control the microstructure of the aluminium alloy ingot by the higher penetrability of lower frequency electromagnetic field in metallic melt. To improve the quality of 7050 aluminium alloy ingots, a low frequency electromagnetic field was applied during the conventional hot-top casting process. The experimental results showed that when the lower frequency electromagnetic field is turned off during the hot-top casting process, cold folding appears, and the as-cast structure becomes very coarse as shown in Figure 2. Moreover, the thickness of the shell zone is much thinner during the low frequency electromagnetic hot-top casting process than during the conventional hot-top casting process [66].

When a low frequency electromagnetic field is applied during the casting process, the alternating current generates a time varying magnetic field in the melt, which gives rise to an induced current in the melt. Therefore, the melt is subjected to electromagnetic body forces caused by the interaction of the induced current and the magnetic field. Another characteristic of the electromagnetic field is the presence of a fringe effect consisting of a pronounced inclination of the magnetic field lines toward the axis of symmetry of the ingot. Therefore, the Lorentz force consists of two parts expressed as follows:

$$
F=-\frac{1}{2 \mu} \nabla(B)^{2}+\frac{1}{\mu}(B \cdot \nabla) B
$$

where $F, B$ and $\mu$ are Lorentz force density vector, magnetic flux density vector, and permeability, respectively. The first part of eq. (1) is a potential force balanced by the static pressure of the melt $(\mathrm{Fr})$, the second part is a rotational component which results in a forced convection in the melt $(F z)$. The natural convection near the mold wall can be changed into a forced convection by this rotational force $(F z)$. The flow of molten metal under the overhang is intensified, the liquidity of the melt near the meniscus becomes good, and the "dead zone" with poor liquidity is minimized

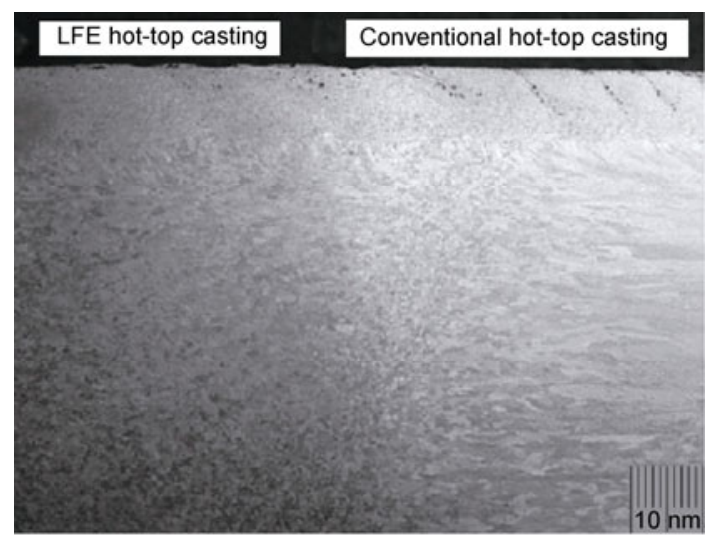

Figure 2 Macrostructure of the transition region of the ingot. or even disappears. So, the depth of cold fold is reduced as shown in Figure 2.

\section{Conclusions}

The properties of aluminium alloys are crucial for the industrial application. The sizes and shapes of grains are important in determining the performance of aluminium alloys. The modification of microstructure during solidification process has been a research focus. Adding alloy elements, using grain refiners and applying physical fields are the main methods for controlling the solidification structure. In this paper, we presented an overview of the methods for microstructure control. Several alloy elements such as Sc, $\mathrm{Er}, \mathrm{Zr}, \mathrm{V}$, etc. used for microstructure control were listed and the main grain refining mechanism of alloy elements was illustrated. Some grain refiners and the poisoning of the grain refiner action after addition of $0.05 \mathrm{wt} \% \mathrm{Zr}$ were introduced. Furthermore, the mechanical field can be used to condition the melt prior to solidification, and electromagnetic field can be used to stir the melt during the solidification process. This review demonstrated that the microstructure and properties of aluminium alloys can be controlled by different methods. However, there are still some technical problems to deal with. New alloy elements, grain refiners and physical fields for microstructure control can be developed by future solidification researches.

This work was supported by the National Basic Research Program of China (2012CB723307 and 2012CB619506), the National Key Technology Research and Development Program of the Ministry of Science and Technology of China (2011BAE21B01), the National Natural Science Foundation of China (51071042 and 51204045), the Wuhan National High Magnetic Field Center (201103), the Fundamental Research Funds for the Central Universities (N090109001 and N100309002), Liaoning Provincial Doctoral Startup Fund (20101036), and China Postdoctoral Science Foundation (20100481193).

1 Dong H. High performance steels: Initiative and practice. Sci China Tech Sci, 2012, 55: 1774-1790

2 Nie W J, Wang X M, Wu S J, et al. Stress-strain behavior of multiphase high performance structural steel. Sci China Tech Sci, 2012, 55: 1791-1796

3 Sanghoon K, Donghwan K, Tae-Won K, et al. Fatigue crack growth behavior of the simulated HAZ of $800 \mathrm{MPa}$ grade high-performance steel. Mater Sci Eng A, 2011, 528: 2331-2338

4 Li L, Gao Y, Zhu N Q, et al. Technology for high performance TRIP steel. Sci China Tech Sci, 2012, 55: 1823-1826

5 Yang K, Ren Y B, Wan P. High nitrogen nickel-free austenitic stainless steel: A promising coronary stent material. Sci China Tech Sci, 2012, 55: 329-340

6 Sun X J, Li Z D, Yong Q L, et al. Third generation high strength low alloy steels with improved toughness. Sci China Tech Sci, 2012, 55: 1797-1805

7 Latpirte F, Wei X D, Feinberg Z D, et al. Design and identification of high performance steel alloys for structures subjected to underwater impulsive loading. Int J Solids Struct, 2012, 49: 1573-1587

8 Xiao N M, Chen Y, Li D Z, et al. Progress in mesoscopic modeling 
of microstructure evolution in steels. Sci China Tech Sci, 2012, 55: 341-356

9 Chen M M, Wu R M, Liu H P, et al. An ultrahigh strength steel produced through deformation-induced ferrite transformation and Q\&P process. Sci China Tech Sci, 2012, 55: 1827-1832

10 Wang G Y, Zhang Y S, Tian X W, et al. Austenite/martensite structure and corresponding ultrahigh strength and high ductility of steels processed by Q\&P techniques. Sci China Tech Sci, 2012, 55: 1844-1851

11 Zhang S Q, Guo W L, Li H, et al. Experimental investigation of three-dimensional mixed-mode fracture of a titanium alloy at room and elevated temperatures. Sci China Tech Sci, 2011, 54: 2760-2767

12 Zhang T Y, Xie T. Effect of electrostatic tractions on the fracture behavior of a dielectric material under mechanical and/or electric loading. Sci China Tech Sci, 2012, 55: 2391-2403

13 Bian X B, Zhang S C, Zhang J C, et al. A new method to optimize the fracture geometry of a frac-packed well in unconsolidated sandstone heavy oil reservoirs. Sci China Tech Sci, 2012, 55: 1725-1731

14 Liu Y R, Chang Q, Yang Q, et al. Fracture analysis of rock mass based on 3-D nonlinear finite element method. Sci China Tech Sci, 2011, 54: 556-564

15 Zuo Y, Cui J, Dong J, et al. Effects of low frequency electromagnetic field on the as-cast microstructures and mechanical properties of superhigh strength aluminum alloy. Mater Sci Eng A, 2005, 408: 176181

16 Chen J, Yan W, Li B, et al. Microstructure and texture evolution of cold drawing $<110>$ single crystal copper. Sci China Tech Sci, 2011, 54: $1551-1559$

17 Li W, Xu P, Zhou H C, et al. Advanced functional nanomaterials with microemulsion phase. Sci China Tech Sci, 2012, 55: 15511559

18 Fang G L, Chen G, Wang X, et al. Synthesis and luminescence of single crystalline $\mathrm{Bi}_{2} \mathrm{O}_{3}$ nanosheets. Sci China Tech Sci, 2011, 54: $19-22$

19 Zhang H, Xu Q Y, Tang N, et al. Numerical simulation of microstructure evolution during directional solidification process in directional solidified (DS) turbine blades. Sci China Tech Sci, 2011, 54: 3191-3202

20 Li B C, Zhao G P, Lu T J. Low strain rate compressive behavior of high porosity closed-cell aluminum foams. Sci China Tech Sci, 2012, 55: 451-463

21 Yao K F. Amorphous alloys-A kind of promising high-performance materials. Chin Sci Bull, 2011, 56: 3895-3896

22 Wang J. Focuses of material science development in recent years. Sci China Tech Sci, 2011, 54: 1645-1648

23 Huang W D, Wang L L. Solidification researches using transparent model material-A review. Sci China Tech Sci, 2012, 55: 377-386

24 Yang $\mathrm{H}, \mathrm{Wu} \mathrm{C}, \mathrm{Li} \mathrm{H} \mathrm{W}$, et al. Review on cellular automata simulations of microstructure evolution during metal forming process: Grain coarsening, recrystallization and phase transformation. Sci China Tech Sci, 2011, 54: 2107-2118

25 Du Y, Zhang L J, Cui S L, et al. Atomic mobilities and diffusivities in Al alloys. Sci China Tech Sci, 2012, 55: 306-328

26 Gao L, Zhou J, Sun Z M, et al. First-principles calculations of the $\beta^{\prime}-\mathrm{Mg}_{7} \mathrm{Gd}$ precipitate in Mg-Gd binary alloys. Chin Sci Bull, 2011, 56: $1142-1146$

27 Peng L, Fan J Y, Li Y R, et al. Two-dimensional numerical simulation of thermocapillary convection in detached solidification. Sci China Tech Sci, 2012, 55: 527-536

28 Huang Z Q, Yao J, Wang Y Y, et al. Numerical study on two-phase flow through fractured porous media. Sci China Tech Sci, 2011, 54: 2412-2420

29 Zhan N Y, Gao Q, Bai L, et al. Experimental research on nonlinear characteristics of natural convection in a 3-D shallow cavity. Sci China Tech Sci, 2011, 54: 3304-3310

30 Xia X Z, Zhang Q, Wang H, et al. The numerical simulation of interface crack propagation without re-meshing. Sci China Tech Sci,
2011, 54: 1923-1929

31 Wang D G, Wang H J, Xiong J H, et al. Characteristic-based operator-splitting finite element method for Navier-Stokes equations. Sci China Tech Sci, 2011, 54: 2157-2166

32 Ro K, Ryou H S. Development of the modified $k-\varepsilon$ turbulence model of power-law fluid for engineering applications. Sci China Tech Sci, 2012, 55: 276-284

33 Chen Y C, Wu Y T, Ren N, et al. Experimental study of viscosity characteristics of high-temperature heat transfer molten salts. Sci China Tech Sci, 2011, 54: 3022-3026

34 Li N L, Huang G J, Xin R L, et al. Influence of extrusion ratio on microstructure and texture developments of high-temperature extruded AZ31 Mg alloy. Sci China Tech Sci, 2012, 55: 490-495

35 Fu S H, Zhang Q C, Hu Q, et al. The influence of temperature on the PLC effect in Al-Mg alloy. Sci China Tech Sci, 2011, 54: 1389-1393

36 Wang C P, Li F G, Wang L, et al. Review on modified and novel techniques of severe plastic deformation. Sci China Tech Sci, 2012, 55: 2377-2390

37 Kaibyshev R, Musin F, Lesuer D R, et al. Superplastic behavior of an Al-Mg alloy at elevated temperatures. Mater Sci Eng A, 2003, 342: 169-177

38 Wang H Y, An Y Q, Li C Y, et al. The research progress of rare earth application in aluminum and aluminum alloys (in Chinese). Chin Rare Earths, 2012, 33: 74-80

39 Marat G, Viktor T, Valerij Z, et al. Solidification behaviour and the effects of homogenisation on the structure of an Al-Cu-Mg-Ag-Sc alloy. J Alloy Compd, 2011, 509: 9497-9507

40 Nie Z R, Wen S P, Li B L, et al. Research progress of Er-containing aluminum alloy (in Chinese). Chin J Nonferrous Met, 2011, 21: 2361-2370

41 Wang X J, Cong F G, Zhu Q F, et al. Effect of trace element vanadium on superplasticity of 5083 aluminium alloy sheets. Sci China Tech Sci, 2012, 55: 510-514

42 Hiroki A, Kozo O, Ken K, et al. Effect of $\mathrm{Zr}$ addition on dynamic recrystallization during hot extrusion in Al alloys. Mater Trans, 2005, 46: $211-214$

43 Zhang Y Y, Deng Y L, Wan L, et al. Effects of precipitation of $\mathrm{Al}_{3} \mathrm{Zr}$ particles on microstructures, textures and properties of $\mathrm{Al}-\mathrm{Zn}-\mathrm{Mg}-\mathrm{Cu}$ alloy hot-rolled plate (in Chinese). Chin J Nonferrous Met, 2011, 22 : 358-364

44 Senkov O N, Miracle D B, Milman Y V, et al. Low temperature mechanical properties of scandium-modified $\mathrm{Al}-\mathrm{Zn}-\mathrm{Mg}-\mathrm{Cu}$ alloys. Mater Sci Forum, 2002, 396-402: 1127-1132

45 Lidia L D, Jan D, Wojciech M, et al. Microstructure of rapidly solidified $\mathrm{Al}-12 \mathrm{Zn}-3 \mathrm{Mg}-1.5 \mathrm{Cu}$ alloy with $\mathrm{Zr}$ and $\mathrm{Sc}$ additions. Mater Trans, 2011, 52: 309-314

46 Gezer B T, Toptan F, Daglilar S, et al. Production of Al-Ti-C grain refiners with the addition of elemental carbon. Mater Des, 2010, 31: 30-35

47 Nie J F, Ma X G, Li P T, et al. Effect of B/C ratio on the microstructure and grain refining efficiency of Al-Ti-C-B master alloy. J Alloy Compd, 2011, 509: 1119-1123

48 Peng J H, Deng Y F, He J T. Study on the interaction of rare earth (La) and strontium with titanium and boron in the Al-Ti-B based master alloy. Adv Mater Res, 2011, 311-313: 1017-1020

49 Doheim M A, Omran A M, Sayed G A, et al. Evaluation of Al-Ti-C master alloys as grain refiner for aluminum and its alloys. Metall Trans A, 2011, 42: 2862-2867

50 Chen Y J, Xu Q Y, Huang T Y. Development of research on grain ref iners for aluminum alloys (in Chinese). Mater Rev, 2006, 20: 57-61

51 Bunn A M, Evans P V, Bristow D J, et al. Modelling of the effectiveness of Al-Ti-B refiners in commercial purity aluminum. In: Welch B, ed. Light Metals. Warrendale, PA: TMS, 1998. 963-968

52 Bunn A M, Schumacher P, Kearns M A, et al. Grain refinement by Al-Ti-B alloys in aluminium melts: A study of the mechanisms of poisoning by zirconium. Mater Sci Technol, 1999, 15: 1115-1122

53 Xiao Z B, Deng Y L, Tang J G, et al. Poisoning mechanism of Zr on 
grain refiner of Al-Ti-C and Al-Ti-B (in Chinese). Chin J Nonferrous Met, 2012, 22: 371-379

54 Huang X R, Han Z Q, Liu B C. Study on the effect of pressure on the equilibrium and stability of the solid-liquid interface in solidification of binary alloys. Sci China Tech Sci, 2011, 54: 479-483

55 Zhou Y Z, Sun X F. Effect of solidification rate on competitive grain growth in directional solidification of a nickel-base superalloy. Sci China Tech Sci, 2012, 55: 1327-1334

56 Sun J J, Tian X L, Zhan C W, et al. Structure correlation of $\mathrm{Al}_{71.6} \mathrm{Ge}_{28.4}$ eutectic alloy between liquid and solid state. Chin Sci Bull, 2010, 55: 761-765

57 Chai L J, Luan B F, Chen J W, et al. Effect of cooling rate on $\beta \rightarrow \alpha$ transformation during quenching of a $\mathrm{Zr}-0.85 \mathrm{Sn}-0.4 \mathrm{Nb}-0.4 \mathrm{Fe}-0.1 \mathrm{Cr}-$ 0.05Cu alloy. Sci China Tech Sci, 2012, 55: 2960-2964

58 Tong G X, Hua Q, Wu W H, et al. Effect of liquid-solid ratio on the morphology, structure, conductivity, and electromagnetic characteristics of iron particles. Sci China Tech Sci, 2011, 54: 484-489

59 Fan Z, Wang Y, Xia M, et al. Enhanced heterogeneous nucleation in AZ91D alloy by intensive melt shearing. Acta Mater, 2009, 57: 4891-4901
60 Lu Y P, Li G B, Du Y Y, et al. Electromagnetic modification of faceted-faceted $\mathrm{Ni}_{31} \mathrm{Si}_{12}-\mathrm{Ni}_{2} \mathrm{Si}$ eutectic alloy. Chin Sci Bull, 2012, 57: 1595-1599

61 Zhai W, Hong Z X, Xie W J, et al. Dynamic solidification of $\mathrm{Sn}-38.1 \% \mathrm{~Pb}$ eutectic alloy within ultrasonic field. Chin Sci Bull, 2011, 56: 89-95

62 Zuo Y, Li H, Jiang B, et al. Refining grain structure and porosity of an aluminium alloy with intensive melt shearing. Scr Mater, 2011, 64: $209-212$

63 Getselev Z V. Casting in an electromagnetic mold. J Met, 1971, 23: 38-43

64 Vives C. Electromagnetic refining of aluminum alloys by the CERM process. Metall Trans B, 1989, 20: 623-643

65 Zhang B J, Lu G M, Cui J Z. Effect of electromagnetic frequency on microstructures of continuous casting aluminum alloys. Mater Sci Technol, 2002, 18: 401-403

66 Wang X J, Cui J Z, Zuo Y B, et al. Effects of low-frequency electromagnetic field on the surface quality of 7050 aluminum alloy ingots during the hot-top casting process. Int J Min Met Mater, 2011, 18: $165-168$

Open Access This article is distributed under the terms of the Creative Commons Attribution License which permits any use, distribution, and reproduction in any medium, provided the original author(s) and source are credited. 